\title{
Sizing and operation of energy storage by Power-to-Gas and Underwater Compressed Air systems applied to offshore wind power generation
}

\author{
Elena Crespi $^{1}$, Luca Mammoliti ${ }^{1}$, Paolo Colbertaldo ${ }^{1}$, Paolo Silva ${ }^{1}$, and Giulio Guandalini ${ }^{1, *}$ \\ ${ }^{1}$ Group of Energy Conversion Systems, Department of Energy, Politecnico di Milano, Via \\ Lambruschini 4A, 20156, Milan, Italy
}

\begin{abstract}
Among the possible solutions for large-scale renewable energy storage, Power-to-Gas (P2G) and Compressed Air Energy Storage (CAES) appear very promising. In this work, $\mathrm{P} 2 \mathrm{G}$ and an innovative type of CAES based on underwater storage volumes (UW-CAES) are compared from a techno-economic point of view, when applied in combination with a $48 \mathrm{MW}_{\mathrm{e}}$ offshore wind power plant, selecting an appropriate location for both high productivity and favorable seabed depth. An optimization model is employed to study the system design and operation, maximizing the lifetime plant profitability, while considering differential installation and operation costs, market values of the products (i.e., hydrogen and electricity), and technological constraints. In the current economic and technological scenario, the resulting $\mathrm{P} 2 \mathrm{G}$ system has a nominal power equivalent to about $10 \%$ of the wind park capacity, with a small hydrogen storage buffer. On the other hand, the compressor and the turbine of the UWCAES have a nominal power close to the full wind farm capacity, and large underwater compressed air tanks are required. Both options significantly impact the wind plant management but the most beneficial applications of the two systems are different: the P2G results in a compact and flexible unit, whereas the UW-CAES is able to exploit a higher average conversion efficiency (about $80 \%$ round-trip) against a much higher installed power and investment cost. Anyway, considering the current framework, the resulting economics are still inadequate, but their competitiveness can improve compatible with the expected evolution of energy markets in the next future.
\end{abstract}

\section{Introduction}

The global energy consumption has seen a huge increase in the last centuries, supported mainly by fossil fuels, but in the last decades new installations have largely moved towards renewable energy sources (RES). In fact, RES installed capacity in the world has almost tripled with respect to the beginning of the 2000s, with a huge spread of wind and solar energy systems, especially for electricity generation. In conjunction with the greater diffusion and

\footnotetext{
*Corresponding author: giulio.guandalini@polimi.it
} 
share in the generation mix, the cost-effectiveness of renewable power generation technologies has reached historic levels [1]. Onshore/offshore wind and solar photovoltaic can now all provide electricity competitively compared to fossil fuel-fired power plants. Thus, the integration of renewable technologies, especially non-programmable ones, is the most disputed factor in the growth of sustainable electricity supply [2]. First of all, dispatching problems must be faced, as the unpredictable variability of generation, which is due to the aleatory nature of the sources, entails considerable difficulties for the Transmission System Operator (TSO) in guaranteeing the continuous balancing of supply and demand. When it is not able to respect the scheduled program, the plant indirectly carries out an unbalancing action on the power grid. In addition, problems related to increasing grid congestion, unpredictable energy transits in the grid in terms of either quantity or direction, and the fact that conventional plants are called upon to play a role in covering concentrated load peaks with a general efficiency loss must be faced. Moreover, the greater penetration of non-programmable RES affects the electricity market, and in particular the implicit auction mechanism that characterizes the definition of electricity prices in the day-ahead market (DAM). The spinning reserve provision for balancing services also becomes an issue. For the reasons mentioned above, solutions to store and manage energy flows and to extend the flexibility of the electric grid are today widely debated and researched. Energy storage systems can be allocated into the grid in order to store energy and release it when needed, contributing to the balancing of the grid and to making electricity more dispatchable $[3,4]$.

Among the various possible technologies, two promising options suitable for long-term and large-scale storage are studied in this work: a Power-to-Gas (P2G) system, storing electricity through the production of green hydrogen, and an innovative Compressed Air Energy Storage system based on Under-Water storage volumes (UW-CAES) [5-8]. Both storage technologies are investigated in combination with an offshore wind farm composed of floating turbines, for which a preliminary sizing procedure is assumed. A techno-economic Mixed Integer Linear Programming (MILP) optimization model is developed for design and operation evaluation. In fact, the model aims at optimizing the configuration, the size, and the hourly operation of each storage plant - separately - to maximize the economic revenues over the entire lifetime. The main outcomes in terms of energy balance, economic performance, and environmental impact are then analyzed, in order to give an in-depth view of these two storage technologies and the potential advantages that their introduction entails. A case study is here presented, considering a hypothetical wind farm located in the South of Sardinia, with the aim to provide a methodology and a general overview of the different behavior of the two solutions. A case-by-case analysis is required for specific applications evaluation and the general identification of the most suitable conditions for each energy storage solution is left to more extensive works.

\section{System configurations}

The investigated energy storage solution is based on the integration of a floating wind farm either with a P2G system or a UW-CAES unit. In the following subsections, a brief overview of the involved technologies is provided.

\subsection{Floating wind farm}

Floating wind turbines represent a key research trend in the context of offshore wind energy in the recent years. They have the potential to significantly increase the sea areas available for offshore wind applications, especially in countries with deep waters, allowing to circumvent the positioning limits that fixed-foundation offshore turbines have. Locating wind farms further off the shore can also reduce visual impact, provide better accommodation for 
fishing and shipping routes, and reach areas of stronger and more consistent wind speeds. There are various flotation technologies ranging from semi-submersible to spar-buoy or tension-leg platform. More than 30 concepts are currently under development from 11 different countries, mostly in Europe [9]. Data taken from these projects, although affected by uncertainty as there has not yet been a full development on the market, seem to demonstrate that the levelized cost of electricity from floating turbines is in line with respect to fixed-foundation turbines, proving that this technology has the potential to become highly competitive and could establish itself on the market in the years to come. Commercial floating wind turbines are mostly at the early phase of development, with several single turbine prototypes installed since 2007. The first operational floating wind farm was Hywind Scotland, developed by Equinor ASA and commissioned in October 2017, consisting of five $6 \mathrm{MW}$ turbines with a total installed capacity of $30 \mathrm{MW}[10,11]$. The largest turbine ever installed on a floating platform is part of the WindFloat Atlantic project by Principle Power, a site under construction off the coast of Portugal, which consists of three V164-8.4 MW wind turbines mounted on the semi-submersible WindFloat platforms that are anchored to the seabed at a water depth of $100 \mathrm{~m}$. The first of the three platforms was successfully connected to the grid on December $31^{\text {st }}, 2019$. The other two units will be connected successively, until they reach a total power of $25 \mathrm{MW}_{\mathrm{e}}$ [12].

From the point of view of this work, the floating solution is interesting because of the required deep seabed for underwater air storage, as discussed in the further paragraphs. Indeed, the 400-1400 m depths expected for reasonable pressure levels are in fact not compatible with wind farms adopting concrete foundations.

\subsection{Power-to-gas (P2G)}

The idea behind the concept of Power-to-Gas (P2G) consists in exploiting the electricity produced by electrical renewable sources for the production of hydrogen through electrolysis (see Fig. 1). The energy stored as chemical energy can be exploited in several final uses, which can be thermal, fuel for mobility applications, re-conversion to electricity, or synthesis of liquid fuels or chemicals. This concept, which integrates several energy sectors by means of hydrogen as an intermediate energy vector, is known as sector coupling, and it is the driving force of the rising interest in hydrogen technologies because of the high decarbonization potential.

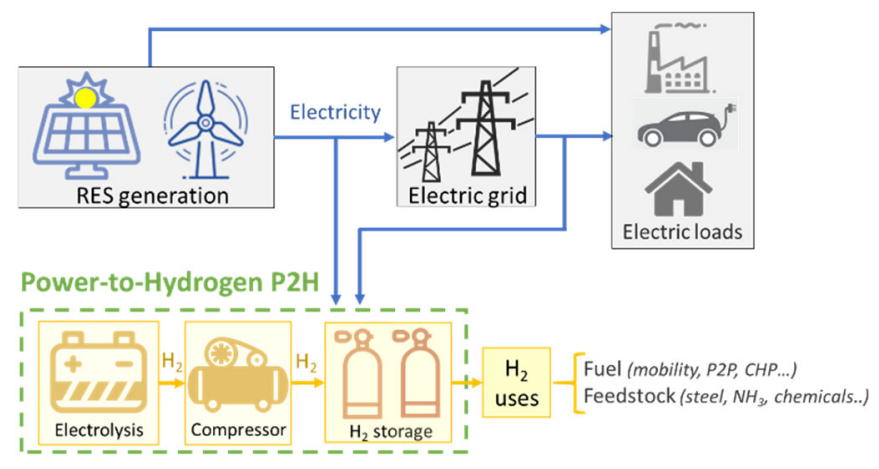

Fig. 1. Schematization of a $\mathrm{P} 2 \mathrm{G}$ chain in a sector coupling approach (from [13]).

Nowadays, only $5 \%$ of hydrogen production worldwide comes from water electrolysis. The electrolysis process is electrochemical, based on water decomposition and charge 
transfers through internal membranes and external electric circuits. The conversion (electricity to hydrogen heating value) is potentially high, but several losses reduce the global performance. The research effort to reduce cell voltage, increase operating temperature and pressure, reduce costs, and increase durability and reliability is really strong, also because of a recent raising of interest in the technology, driven by the availability of renewable electricity at lower cost [14]. There are three main technologies of electrolytic cells, which differ in structural conformation, electrolyte, and operating conditions: Alkaline Water Electrolysis (AE), Proton Exchange Membrane Electrolysis (PEME), and Solid Oxide Electrolysis (SOE). Despite the higher cost and lower commercial maturity, in this work the PEME technology is selected as the most promising one for direct coupling with fluctuating renewable energy sources. AE is more established and less expensive, but still suffers from load variation issues and compactness, while SOE is not suitable for fast ramping and frequent shut-down [14,15]. In particular, recent projects including high temperature technologies mention ramp rates of 1 to $3{ }^{\circ} \mathrm{C} / \mathrm{min}$ and current variations of 0.04 $0.05 \mathrm{~A} / \mathrm{cm}^{2} / \mathrm{min}[16,17]$, while a commercial unit from Sunfire declares 10 minutes as hot idle ramp time [18]. In comparison, PEME already reaches hot idle ramp time of tens of seconds and cold startup ramp time of few minutes [17]. The system has to match with average hour-by-hour power fluctuations of wind power production in the order of magnitude of $20-40 \%$ of rated power and probability of unexpected zero-wind events of about $10 \%$ [19]. These ramp requirements could become stricter if the storage unit is also designed to provide services to the electric grid.

The main issues of the $\mathrm{P} 2 \mathrm{G}$ concept are related with high investment costs, low technology readiness, poor supply chain energy efficiency, and significant transport and storage problems of the hydrogen itself. In practice, the low energy density of gaseous hydrogen requires high pressure to keep a reasonable tank size, or alternative storage solutions (liquefaction, hydrides, ...) [20]. Among these, a transition strategy proposed to overcome the technical difficulties of hydrogen storage and the absence of a dedicated delivery network is the admixing of hydrogen in the natural gas infrastructure (up to $20 \% \%_{\text {vol }}$ ) [21]. The natural gas enriched with hydrogen can then be used by combustors or engines, or separated for uses in pure form in the chemical sector and in electrochemical devices, contributing to the abovementioned sector coupling and fostering decarbonization.

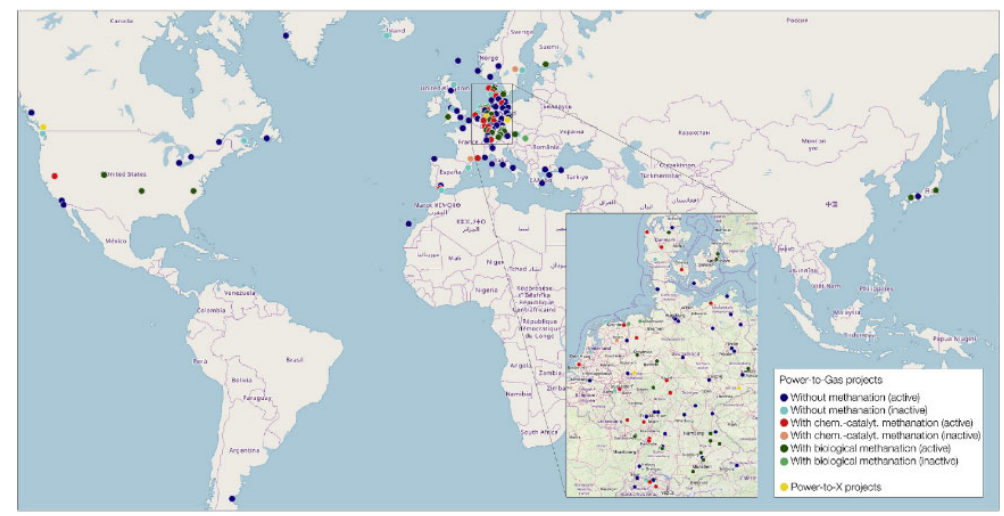

Fig. 2. Review of P2G projects in the world (2019, from [22]).

Despite these criticalities, hydrogen solutions remain relevant because of the possibility of decoupling power and energy capacity in the storage phase, the scalability, and the full decarbonization achieved with this energy vector (i.e., no carbon in the molecule). Consequently, a strong development is foreseen in the next years, in particular in sectors in 
which electrification is not an efficient or feasible solutions. Numerous demonstration and laboratory P2G projects have been developed in the last years. A 2019 review identified 153 completed, operational, and planned projects for the time span from 1993 to 2050 [22]. In particular, $57 \%$ of these projects are based on production, storage, and use of pure hydrogen. As of 2019, 56 P2G hydrogen projects were in operation for a total capacity of $24.1 \mathrm{MW}_{\mathrm{e}}$, 21 of which with injection of the product into a natural gas grid. Most of the projects are located in central Europe, in particular Germany, Denmark, and the Netherlands, but there are also projects in Italy, Spain, United Kingdom, and United States, as shown in Fig. 2.

\subsection{Under-Water Compressed Air Energy Storage (UW-CAES)}

Compressed Air Energy Storage (CAES) is one of the promising methods for large-scale storing of renewable electricity. In CAES plants, energy is stored by compressing the air in a tank and energy is extracted by expanding it during the discharge phase. Both adiabatic and diabatic solutions are possible, depending on the strategy for air heating before expansion, i.e., by means of thermal storage or external fuels combustion, respectively. The UW-CAES (Under-Water Compressed Air Energy Storage) is a particular CAES system that works with underwater tanks, whose structure allows for sea water to enter in the tank itself. The internal pressure is then defined by the constant hydrostatic pressure, depending on the depth, and the system operates with variable volumes. The system is depicted in Fig. 3 and includes: (i) a set of turbomachines (a multistage compressor with intercooling and a turbine); (ii) a thermal energy storage (TES) system with different temperature levels and fluids, designed to recover a large fraction of the compression heat; (iii) an underwater modular compressed air storage structure installed on the seabed and allowing a variable-volume and constant pressure operation; (iv) components aimed at ensuring the operation of the plant, such as heat exchangers, electrical equipment, pumps, and piping.

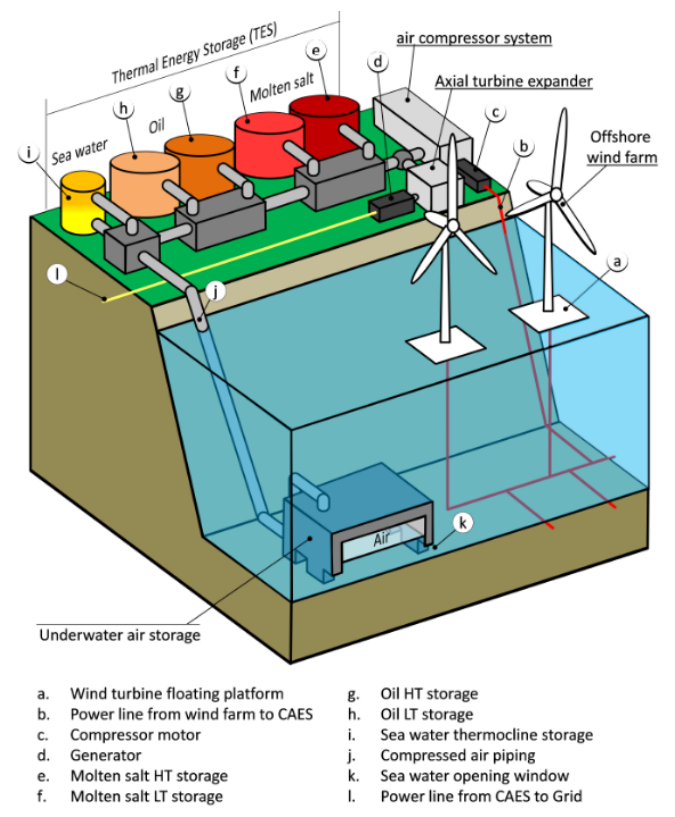

Fig. 3. UW-CAES configuration coupled to an offshore wind farm (from [5]). 
A peculiarity of this solution is that the compressor operates at variable loads, following an oscillating renewable power input, according to the strategy with which the system is regulated. Anyway, the outlet pressure is almost constant, and the flow rate can vary dramatically to follow the power fluctuations. Hence, a complex structure is required to avoid surge conditions, with parallel compression trains and different technological solutions, as discussed in detail in [5]. In addition, the outlet temperature from the compression unit has to be high enough for efficient thermal recovery. Different solutions exist for TES, according to the temperature levels; in this work, a cascade of three tanks containing molten salts $(60 \%$ $\left.\mathrm{NaNO}_{3} / 40 \% \mathrm{KNO}_{3}, 600-290{ }^{\circ} \mathrm{C}\right)$, diathermal oil $\left(290-80{ }^{\circ} \mathrm{C}\right)$, and sea water $\left(80-30{ }^{\circ} \mathrm{C}\right)$ is selected.

The UW-CAES system requires a seabed depth suitable to guarantee the operating pressure of the concrete rigid air tank, which can vary between 40 and 140 bar, and in general requires large spaces for the tanks, basically composed of modules with considerable volumes, in the order of hundreds or thousands of cubic meters. However, in light of the large power generally involved, this technology can potentially provide a service for balancing the grid and improving the dispatchability of electricity from renewable sources, offering the possibility of accumulating energy and avoiding the use of fossil fuels.

The CAES concept is under investigation since the 1970s with the aim of storing power generated by nuclear plants, with the installation of the first plant in the word in Huntorf, Germany in 1978, featuring a nominal power of $290 \mathrm{MW}$. After the huge increase of renewables seen after 2000, this type of technology regained interest due to the variability of those sources and the limits on the grid, and over the years there have been projects in various countries, such as Italy, Japan, USA, Israel, China, and Germany [6]. In 2015, the University of Windsor (Canada), in partnership with Hydrostor, a Toronto-based company, developed the world's first UW-CAES demonstration plant $[23,24]$. However, the difficult regulation of the UW-CAES system and, above all, the strong limits in its remuneration in the light of high investment costs have not yet allowed this technology to establish itself on the market.

\section{Methodology}

In this section, the sizing methodology for the coupled floating wind farm and energy storage unit is presented, considering both the modelling approach and the general assumptions. On the one hand, the wind farm size and productivity are estimated by means of a state-of-theart simulation tool (System Advisor Model, SAM [25]) that includes a database of wind turbines and performance indexes. This approach is assumed to be sufficient, since the focus of this work is the storage unit and the wind profile is only the input for simulations, equal in all the analyzed cases.

On the other hand, the P2G and UW-CAES performances are estimated through a technoeconomic optimization based on Mixed Integer Linear Programming (MILP). The models are implemented in Matlab ${ }^{\circledR}$ through the Yalmip extension [26] and solved with Gurobi ${ }^{\mathrm{TM}}$ Optimizer "branch-and-cut" algorithms [27]. The model solves the energy balance of the system, optimizing the energy flows assigned to each possible output (electricity, hydrogen) considering conversion efficiency of the intermediate components, as detailed in sections 3.3 and 3.4 for P2G and UW-CAES, respectively. In all the cases, the electricity generation from the wind farm, the sale prices of electricity and hydrogen, and the performance of the energy storage units are provided as input and assumed constant, while the output of the simulation are the optimal capacities of the components and the total differential revenue with respect to the wind farm operating on the DAM without any energy storage unit. The objective function, aiming at maximizing the total differential revenues $(\Delta R)$, is shown in Eq. (1). The additional investment $(C A P E X)$ and operational $(O P E X)$ costs are taken into account, i.e., only the costs of the energy storage units. The Capital Recovery Factor (CRF) approach is 
used to allocate the CAPEX as a constant instalment over the entire plant lifetime [28]. The additional (or the reduced amount of) electricity generated $\left(E_{\text {grid }}\right)$ with respect to the base case $\left(E_{\text {base }}\right)$ is remunerated at the DAM electricity price $\left(p_{E E}\right)$. Hydrogen is sold at a constant price $\left(p_{H_{2}}\right)$ considering both the exported amount $\left(E_{H_{2}, \text { exp,tot }}\right)$ and the residual amount in the storage at the end of the period $\left(\Delta E_{H 2, s t}\right)$. Thus, the final size of the system is a tradeoff between the increasing installation cost of large storage plant and the increasing revenues from electricity and hydrogen sold. The optimization model solves the energy balance over all the components with an hourly timestep.

$$
\begin{aligned}
& \max (\Delta R)= \\
& \max \left[-C A P E X \cdot C R F-O P E X+\sum_{t}\left[\left(E_{\text {grid }}^{t}-E_{\text {base }}^{t}\right) \cdot p_{E E}^{t}+E_{\mathrm{H}_{2}, \text { exp }}^{t} \cdot p_{\mathrm{H}_{2}}\right]\right. \\
& \left.\quad+\Delta E_{\mathrm{H}_{2}, \text { st }} \cdot p_{\mathrm{H}_{2}}\right]
\end{aligned}
$$

Details about the implemented models and the general assumptions are presented in the following sections, and then the influence of the main parameters is discussed. Moreover, a complete description of the approach used in this work and the corresponding set of equations, describing the model for a storage system coupled with RES, can be found in [28].

\subsection{Wind farm design and operation}

The first step of the analysis is an assessment of possible sites in Italy, in order to define the optimal position of the wind farm. In fact, a location near the coast is required to allow a correct installation of the floating wind farm (up to $200 \mathrm{~m}$ depth) and, at the same time, a position that guarantees subsequently high depths (between 400 and $1400 \mathrm{~m}$ ) to reach the operating pressures of the UW-CAES air reservoir. The P2G solution also requires a connection to the coast for exporting the hydrogen production. An area with these characteristics is found in the south-west of Sardinia, off the island of San Pietro, where the seabed depth varies from $200 \mathrm{~m}$ to $1000 \mathrm{~m}$ between 30 and $40 \mathrm{~km}$ from the coast, and it is selected for the study. Similar locations are available along both the insular and continental coast (mainly the Tyrrhenian Sea and the areas around the Islands), featuring different wind profiles or seabed shapes. The numerical results are clearly strongly influenced by the selected location, but the general features and optimal use of each storage solution depends on their specific structure, as discussed later, while a case-by-case analysis is required to correctly evaluate the economics of each solution.

For the selected area, the hourly wind speed data are available from [29] and the performance of the hypothetical offshore wind plant are estimated through the software SAM (System Advisor Model) [25]. This allows both to identify a preliminary sizing of the wind farm and to simulate the plant operation considering wake losses, plant availability, electrical and environmental constraints, and turbine performance losses. Among the wind turbines available in the database, 24 Vestas V110-2.0 MW turbines (cut-in speed $3 \mathrm{~m} / \mathrm{s}$, cut-off speed $20 \mathrm{~m} / \mathrm{s}$, rated speed $11.5 \mathrm{~m} / \mathrm{s}$, rated power $2 \mathrm{MW}_{\mathrm{e}}$ ) are selected for a total rated power of $48 \mathrm{MW}_{\mathrm{e}}$. This solution best suits the characteristics of the wind data, resulting in an optimal plant configuration based on energy (capacity factor 38.8\%, $163 \mathrm{GWh}_{\mathrm{e}} /$ year) and economic evaluations (LCOE 68.2€/MWh). The alternative layouts and models suitable for the wind distribution result in lower capacity factors (21-35\%) or higher LCOE (up to $106 € / \mathrm{MWh}$ ). The expected wind speed distribution and electricity output profile are shown in Fig. 4. 

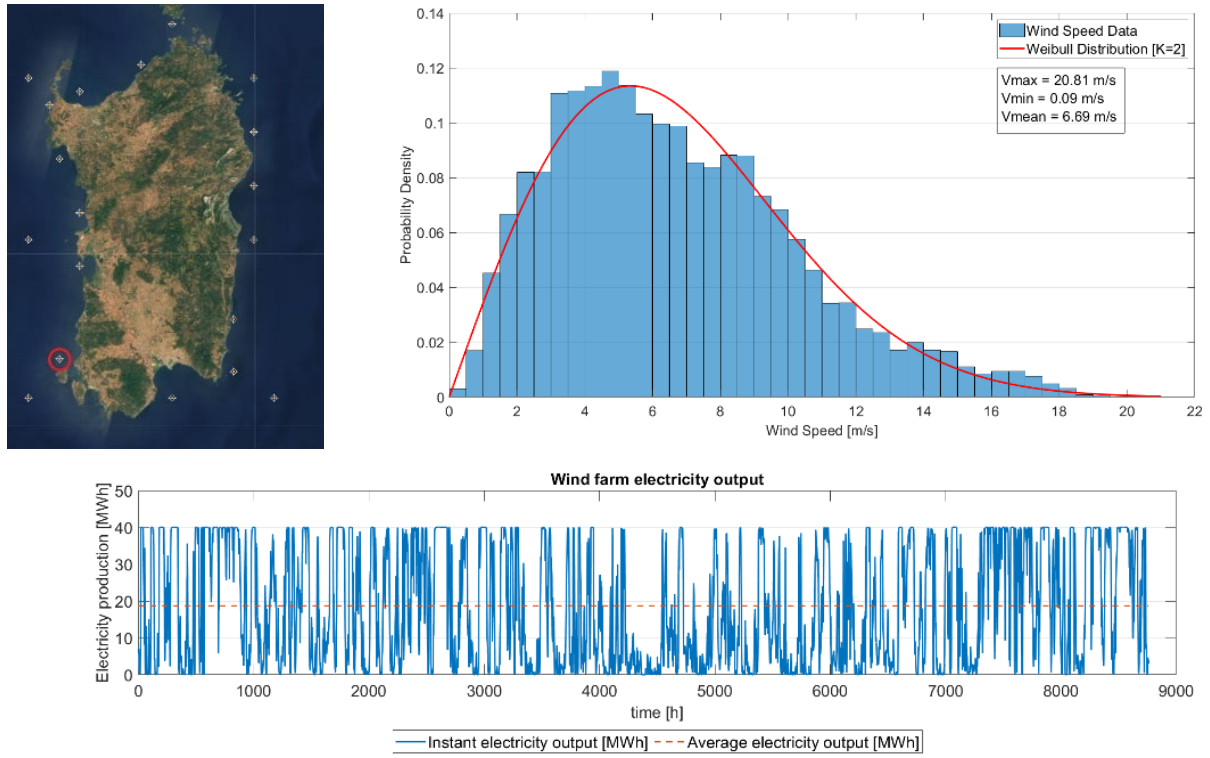

Fig. 4. (a) Position of the selected location with respect to the Sardinia island; (b) wind speed distribution and Weibull function approximation of the actual wind data for the considered site (2019, [29]); and (c) expected electricity generation from the $48 \mathrm{MW}_{\mathrm{e}}$ wind farm [25].

With respect to the nominal installed capacity, the simulated maximum plant generation is about $40 \mathrm{MW}_{\mathrm{e}}$ due to abovementioned real effects that the tool takes into account.

The design of the wind farm is then kept constant in all the following simulations of the energy storage systems. In addition, the analysis is differential with respect to the benchmark case, which considers the wind farm operating on the DAM without any storage system.

\subsection{Power-to-Gas model and assumptions}

Regarding the $\mathrm{P} 2 \mathrm{G}$ system, the configuration adopted in this work considers the injection of the produced hydrogen in the natural gas grid infrastructure, avoiding the costs and the additional complexity of large hydrogen storage and reconversion units (i.e., fuel cell or hydrogen gas turbine). In addition, the large capacity of the natural gas grid infrastructure makes in principle the system suitable for storing large quantities of renewable energy. The simulated configuration, including the optimized quantities, is schematically shown in Fig. 5 . The electricity generated by the wind farm $\left(E_{\text {wind }}\right)$ can be directly sold to the power grid $\left(E_{\text {grid }}\right)$ or sent to the electrolysis modules to produce hydrogen $\left(E_{\text {elc }}\right)$. The generated hydrogen $\left(E_{H 2, p r o d}\right)$ is directly injected into the natural gas grid $\left(E_{H 2, \text { grid }}\right)$, assuming reference natural gas flow rates and caps to the hydrogen fraction, as described in section 3.4. Since a limit on the allowed hydrogen fraction in the natural gas could be imposed by the TSO, the temporary excess of production is stored in compressed-hydrogen metallic tanks (200 bar) after a compression step. In particular, a lumped approach with a limit of $10 \%_{\mathrm{vol}}$ is assumed, according to the recent experience of the Italian TSO [30,31]. The compression energy is provided by the wind farm itself $\left(E_{c m p}\right)$, while the energy content of the storage is tracked $\left(E_{H 2, s t}\right)$. The additional option of electricity generation via $\mathrm{P} 2 \mathrm{P}$, reported with dotted lines in Fig. 5, is not considered in this work and will be evaluated in the future according to the preliminary results of this study. 


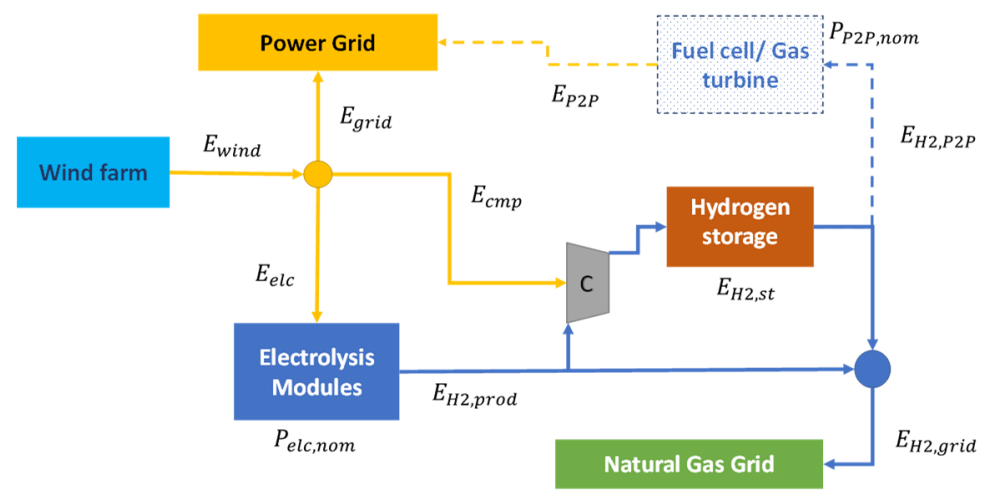

Fig. 5. The P2G configuration implemented in the model and optimized energy flows. The P2P solution is not considered in this work.

The model optimizes the energy flows in each time step, the storage capacity $\left(E_{H 2, s t \text { max }}\right)$, and the electrolysis nominal installed power $\left(P_{\text {elc,nom }}\right)$. Additional constraints include penalties for switching the electrolysis modules on and off $(30 \%$ of the production is lost in the first hour of operation due to low purity and safety procedures) and limits for hydrogen injection in the natural gas infrastructure. The plant lifetime is 20 years, resulting in a capital recovery factor $(\mathrm{CRF})$ of $9.4 \% /$ year $(\mathrm{WACC}=7 \%)$.

For the P2G system, the following assumptions are made:

- The electrolysis unit has an investment cost of $800 € / \mathrm{kW}_{\mathrm{e}}$ and operational costs equal to $2 \%$ of the CAPEX. After 10 years, stacks substitution is planned, corresponding to $60 \%$ of the initial investment. The electricity-to-hydrogen conversion efficiency is assumed constant and equal to $65 \%$ LHV $[14,15,32]$. The model considers installing a discrete number of modules, each with a nominal capacity of $500 \mathrm{~kW}_{\mathrm{e}}$.

- The hydrogen storage system, including the compression unit, has an investment cost of $30,000 € / \mathrm{MWh}_{\mathrm{LHV}}$ (about $1000 € / \mathrm{kg}$ ), while operational costs equal to $1 \%$ of the CAPEX are assumed.

- An additional $2.5 \%$ is added to CAPEX to consider internal piping, instrumentation, and other minor equipment.

\subsection{UW-CAES model and assumptions}

Regarding the UW-CAES system, its configuration is schematically shown in Fig. 6. The electricity generated by the wind farm $\left(E_{\text {wind }}\right)$ can be directly sold to the power grid $\left(E_{\text {grid }}\right)$ or sent to the storage unit to power an air compressor $\left(E_{c m p}\right)$. The compressed air is cooled down to recover the compression heat, storing thermal energy in three tanks containing respectively salt, oil, and water. The air is finally stored in the underwater reservoir, whose volumetric content is tracked $\left(V_{s t, a i r}\right)$. When electricity generation is required, the air from the reservoir is heated up and expanded in a turbine, injecting electricity into the grid $\left(E_{\text {turb }}\right)$.

Also in this case, the model optimizes the energy flows in each time step, the storage capacity $\left(V_{\text {air }, \text { st } \max }\right)$ and the installed CAES power island nominal capacity $\left(P_{\text {cmp,nom }}\right.$ and $\left.P_{\text {turb,nom }}\right)$. The plant lifetime is 30 years, resulting in a CRF of $8.1 \% /$ year (WACC $=7 \%$ ).

For the UW-CAES system, the following assumptions are implemented:

- The Power Island operation is affected by the performance of the components and the costs as detailed in [5]. Reference mass and energy flows are linearly rescaled by the optimization model, while the costs are corrected with a power law featuring a scale 
exponent equal to 0.66 for the thermal storage and heat exchangers [33]. Turbomachinery costs are estimated as a function of the nominal power and of the flow rate, according to the approach presented in [5]. The size of the thermal storage units is assumed proportional to the underwater air tank, according to the reference case in [5].

- The underwater air tank has an investment cost of $40 € / \mathrm{m}^{3}$. The underwater piping that connects the power island to the reservoir has an installed cost of $5 € / \mathrm{m}$ and its length is estimated according to the coast shape. The pressure in the underwater reservoir depends only on the depth of the tank position, influencing costs and performance; a reference value of 80 bar is assumed (about $800 \mathrm{~m} \mathrm{s.1.m}$.). For this depth, the length of the pipe is about $40 \mathrm{~km}$. Both the pipeline and the concrete vessels for air are placed at deep water off-shore location, so extra costs due to anchoring system, engineering phase and transportation are included as an additional $50 \%$ on the total installation cost [5].

- $\quad$ Electrical equipment (transformer, converter) and gearbox costs are included from [5]. An additional $10 \%$ is added to CAPEX to consider internal piping, instrumentation, and other minor equipment.

- $\quad$ OPEX for the complete system is $2 \%$ of CAPEX per year.

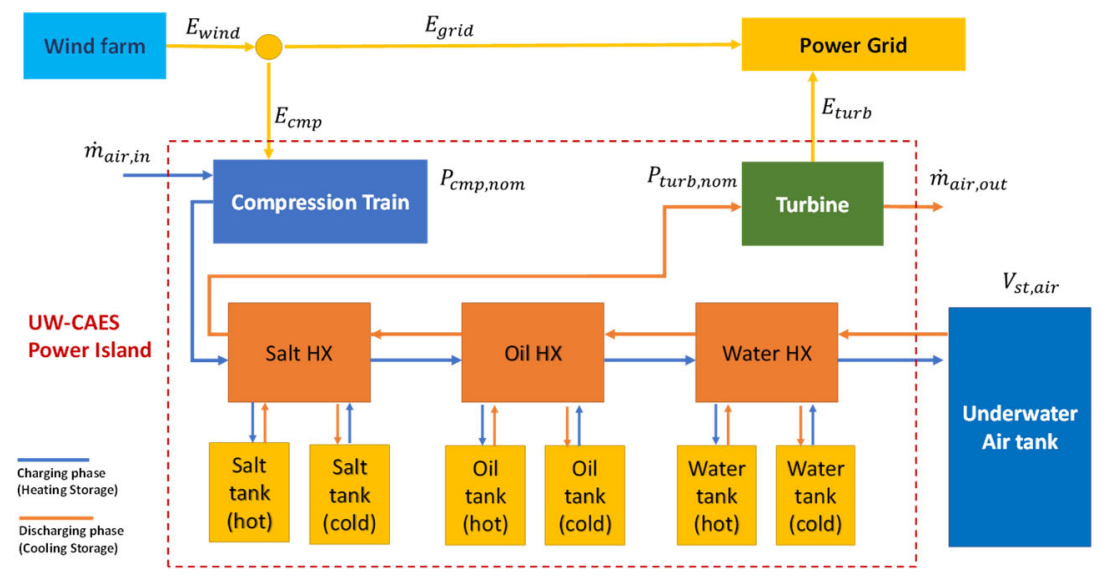

Fig. 6. Schematization of the UW-CAES configuration implemented in the model with optimized energy flows.

A peculiarity of this system is the imposed electrical power consumption to the compressor, while the resulting performance index is the amount of air compressed to the target pressure. This aspect strongly influences the design and the performance of turbomachinery section, hence performance maps calculated in a previous work [5] are assumed and link treated air mass flow rate $\left(m_{\text {air }, i n}\right)$ to the power provided to the compressor.

\subsection{Energy markets and constraints}

The main driving force for the operation strategy is the match between the wind farm power output and the electricity price. The electricity sale price profile refers to the day-ahead market (DAM) results in the Sardinia zone in 2019 [34], with prices ranging most of the time between 30 and $80 € /$ MWhe (see Fig. 7). 


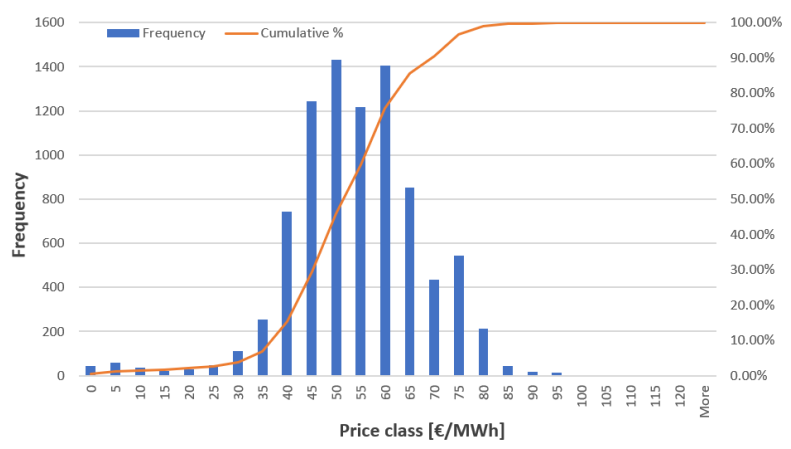

Fig. 7. Electricity price trend on the day-ahead market, Sardinia zone, 2019 [34].

In addition to the revenues from electricity sale, the hydrogen price strongly influences the economic performance of $\mathrm{P} 2 \mathrm{G}$ option. Since there is no implemented open wholesale market for hydrogen and many final uses are possible, it is not easy to identify a unique price and a range of values is investigated. On the methane market, nowadays the average price is between 20 and $30 € / \mathrm{MWh}_{\mathrm{LHV}}$, whereas the expected valorization of hydrogen in the transport sector could reach $120 € / \mathrm{MWh}_{\mathrm{LHV}}$ or more. The hydrogen price is assumed constant during the year, which is the common approach for the natural gas and fuels markets. In practice, the price is much more stable than the electricity one, thanks to the frequent use of long-term bilateral trades and the possibility of storage.

Despite the constant price, the capability of the natural gas infrastructure to receive the hydrogen changes during the year because of technical constraints. The main issues related with hydrogen presence in the natural gas infrastructure are related with materials (e.g., highstrength steel embrittlement, poor sealing capacity of polymers), combustion control (e.g., if not set according to the different gas composition), metering, and regulation limitations (e.g., hydrogen limit for vehicular tanks refilling). Anyway, strong research activities are carried out in this sector to identify the actual limitations and to adapt the infrastructure and the regulation to the evolving scenario. In this work, a maximum percentage of hydrogen equal to $10 \%$ vol is assumed (with reference to a test carried out by the Italian TSO Snam in Contursi Terme in December 2019 [30,31]). A reference natural gas flow profile has also to be defined. The flow profile is calculated from a reference medium-pressure ( $30 \mathrm{bar}$ ) natural gas pipeline average monthly flow rate (see Fig. 8), since Sardinia technically does not have a network of methane pipelines in its territory, at the moment. This lumped approach does not consider local concentration issues but allows for defining critical conditions for the system operation; in addition, the $10 \%$ vol limit is a conservative value with respect to the maximum allowable concentration in relation to material resistance and final equipment acceptance $[21,35]$.
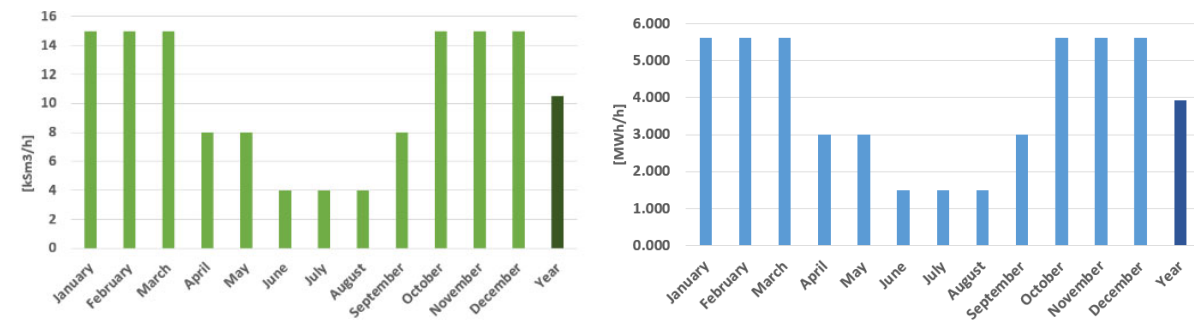

Fig. 8. (a) Average natural gas flow rate and (b) energy flow (LHV) of hydrogen to comply with $10 \%$ vol average limit. 


\section{Results}

In this section, the results of a set of cases simulated for the P2G and the UW-CAES systems are reported. For each system, a sensitivity analysis provides an insight on the influence of the wind farm generation profile, the electricity and hydrogen prices, and the investment costs. The most relevant cases of each technology are then compared in order to assess the strengths and weaknesses of the technologies.

\subsection{P2G results}

The base-case simulation is performed with reference to 2019 wind profile from [29], but the influence of wind profiles is also assessed by means of synthetic profiles functions with the same statistical distribution and persistence characteristics. Investment costs, prices, and technical parameters are the one presented before, while the impact of their variation is described in section 4.1.1. In particular, the revenue from hydrogen is set at $120 € / \mathrm{MWh}_{\mathrm{LHV}}$ in the reference case. From the technical point of view, the wind farm generation profile affects both the design and the operation of the system, resulting in a total installed capacity of the electrolysis modules ranging between 3 and $5 \mathrm{MW}_{\mathrm{e}}$, equivalent to $6-10 \%$ of the wind farm nominal power $\left(48 \mathrm{MW}_{\mathrm{e}}\right)$. The volumes of the hydrogen tanks are also very low, in a range between 0.5 and $2.5 \mathrm{~m}^{3}$ (i.e., about $1.2 \mathrm{MWh}_{\mathrm{LHV}}$ maximum), since the production of hydrogen exceeds the maximum limit of injection into the natural gas network only a few times during the year (i.e., the storage treats about $1.5 \%$ of the produced hydrogen). From the point of view of economics, the investment costs range from about 3 to $5 \mathrm{M} €$ depending on the profile used for the design (corresponding to a total specific cost of about $1000 € / \mathrm{kW}_{\mathrm{e}}$ ), with more than $78 \%$ of the costs related to the electrolysis module. The P2G system presence reduces the revenue from direct electricity sold to the grid, but on the other hand it is compensated by hydrogen export that results in about $25 \%$ of the total revenue (between $75 \mathrm{M} € / \mathrm{y}$ and $110 \mathrm{M€} / \mathrm{y}$ ). With this economic framework, the pay-back time of the system is 15 years, which is way too long to make the investment attractive for investors. It therefore emerges that higher hydrogen prices are necessary to have a positive return on the investment.

\subsubsection{Parameters influence}

As far as concern the P2G system, Table 1 summarizes the simulated cases and gives the reference value of the most relevant parameters.

Table 1 - Overview of assumptions ranges for P2G simulation cases.

\begin{tabular}{lcccc}
\hline Simulation case name & $\begin{array}{c}\text { Hydrogen } \\
\text { price } \\
{[\mathbf{\epsilon} / \mathbf{M W h} \text { LHV] }}\end{array}$ & $\begin{array}{c}\text { Electrolyzer } \\
\text { specific cost } \\
{\left[\mathbf{\epsilon} / \mathbf{k} \mathbf{W}_{\mathbf{e}}\right]}\end{array}$ & $\begin{array}{c}\text { Electrolyser } \\
\text { efficiency } \\
{[\boldsymbol{\%}]}\end{array}$ & $\begin{array}{c}\text { Electricity } \\
\text { price profile }\end{array}$ \\
\hline Base case & 120 & 800 & 65 & GME 2019 \\
\hline Sensitivity 1 & $90 \div 150$ & $400 \div 1000$ & 65 & GME 2019 \\
\hline Sensitivity 2 & $90 \div 150$ & 800 & $65 \div 74$ & GME 2019 \\
\hline Sensitivity 3 & $30 \div 150$ & 800 & 65 & Modified \\
\hline $\mathrm{H}_{2}$ for mobility & $90 \div 150$ & 800 & 65 & GME 2019 \\
\hline
\end{tabular}

The variation of electrolysis specific investment cost and of hydrogen price (Sensitivity 1) is the first scenario considered. In this case, the calculated minimum hydrogen price for positive revenues with the lowest electrolysis investment cost $\left(400 € / \mathrm{kW}_{\mathrm{e}}\right)$ is $90 € / \mathrm{MWh}_{\mathrm{LHV}}$ 
(about $3 € / \mathrm{kg}$ ), while for an average investment cost $\left(800 € / \mathrm{kW}_{\mathrm{e}}\right)$ the limit increases to $110 € / \mathrm{MWh}_{\mathrm{LHV}}$ (about $4 € / \mathrm{kg}$ ). In this last condition, the pay-back time of the plant results between 10 and 6 years with prices between 110 and $150 € / \mathrm{MWh}$. It is clear that these values are not compatible with the current fossil fuels market (50-65€/MWh for gasoline and Diesel fuel, 20-30 €/MWh for natural gas, tax free), but it is a feasible scenario for the 'greening' of the transport and gas sectors (e.g., biomethane $60 € / \mathrm{MWh}$ ), as mentioned before.

The second investigated option (Sensitivity 2) considers an increase of the performance of the electrolysis modules, as expected in the near future thanks to improved technological and market maturity. Due to the high contribution of the component to the total investment, a strong impact in lowering the hydrogen sale price is expected. In the most favorable conditions (high hydrogen price), the model selects to install up to $10 \mathrm{MW}_{\mathrm{e}}$ of electrolysis (instead of 3-5 $\mathrm{MW}_{\mathrm{e}}$ in the base case), which corresponds to about $20 \%$ of the wind farm nominal power. This larger hydrogen production potential also leads to an increase in the hydrogen tank size, to manage the production peaks in periods with low natural gas transit, but the required storage does not exceed $40 \mathrm{~m}^{3}$. In this case, the pay-back time of the P2G system decreases to around 8 years.

In the third sensitivity analysis (Sensitivity 3 ), the effect of a different electricity price structure, combined with wind availability, is tested: (i) smoothing through moving the maximum and minimum peak prices, and (ii) prices reduction in the daily hours ( 9 a.m.5 p.m.) by $40 \%$ or $100 \%$. The goal is to simulate, in a deliberately extreme way, the effect that a greater penetration of RES power plants, which influence the price trend on the DAM market, may have on the profitability of the system. Both the P2G configuration and the base case are recalculated with the new price profiles. The first option does not influence in a relevant way the results, with minor changes in the operation of the system, whose storage capability is already suitable for managing the variations in the daily operation. On the other hand, the second profile yields improved economic conditions for a park with storage options with a reduction of the plant payback time potentially up to a value of 6 years.

Ultimately, a configuration of $\mathrm{P} 2 \mathrm{G}$ aimed at an application in the sustainable mobility sector is studied. The model is adapted to characterize a slightly different plant configuration, modeling a possible supply/demand mechanism for hydrogen. The system no longer feeds hydrogen into the natural gas network but exports it by means of pressurized tankers at 200 bar, with a minimum (600 kg/day) and maximum (2000 kg/day) daily production to be respected. The tankers empty the local storage twice per day. Also in this case, the main revenue is provided by electricity sale to the electric grid, while the hydrogen price must be kept high (120-160€/MWh) for a profitable operation. The largest impact is on the local hydrogen tank that has to manage the production peaks, resulting in volumes up to $150 \mathrm{~m}^{3}$ and investment costs higher than $2 \mathrm{M} €$ (28\% of the total). The total P2G unit investment cost rises to about $1500 € / \mathrm{kW}_{\mathrm{e}}$.

\subsection{UW-CAES results}

A preliminary UW-CAES optimization is performed on shorter periods (i.e., few months) and, in all the cases, the optimization model selects the maximum power allowed for compressor and turbine, equal to $40 \mathrm{MW}_{\mathrm{e}}$ (coinciding with the maximum wind energy generation) and $48 \mathrm{MW}_{\mathrm{e}}$ respectively. Therefore, these values are assumed as parameters, limiting the optimization to operation and storage units sizing, thus also containing the computational effort.

As for $\mathrm{P} 2 \mathrm{G}$, the different wind park generation profiles are tested, but the result is a negative economic performance in all the cases, if the assumptions in section 3.3 are considered, since a specific cost around $3000 € / \mathrm{kW}_{\mathrm{e}}$ is obtained for UW-CAES. A positive revenue is obtained reducing the investment cost of the system to $800 € / \mathrm{kW}_{\mathrm{e}}$, which is then 
assumed in the following analysis. This cost reduction can be seen as a technological improvement or as an incentive for the fully dispatchability of the wind park power. The actual cost reduction is equivalent to about $50 \mathrm{k} € / \mathrm{MW}_{\mathrm{e}} /$ year, taking into account the 30 -year long lifetime, and this is not far from the value offered by the Italian electric TSO TERNA for participation in tertiary regulation services (i.e., availability to substitute missing generation for long periods). Despite the resulting specific investment costs of the UW-CAES technology is basically aligned with $\mathrm{P} 2 \mathrm{G}$ system one (around $1000 € / \mathrm{kW}_{\mathrm{e}}$ ), the optimal economics yields high power flows (about $40 \mathrm{MW}_{\mathrm{e}}$ vs 3-5 $\mathrm{MW}_{\mathrm{e}}$ ) and high storage volumes $\left(20,000-30,000 \mathrm{~m}^{3}\right.$ for the air tank vs. $40 \mathrm{~m}^{3}$ for the hydrogen system, plus the thermal storage volume is around $1000 \mathrm{~m}^{3}$ ). Hence, the two solutions are completely different from the point of view of the size and of the operation.

In any case, pay-back time of the UW-CAES solution is very high (20-30 years), evidencing the need for further reduction in the investment cost. The overall investment cost is between 30 and $35 \mathrm{M} €$, with $45 \%$ of the cost related to turbomachinery, $37 \%$ to thermal energy storage, and about $9 \%$ to the underwater piping and concrete tanks.

\subsubsection{Parameters influence}

As for the P2G system, some sensitivity analyses are carried out on the UW-CAES solution. In particular, the electricity price profile is modified as discussed in section 4.1.1. In this case, both approaches modify the economic framework of the UW-CAES system:

- The profile smoothing further reduces the income from the energy storage unit, which, according to the implemented strategy, mainly exploits the price differences (arbitrage). In this case, the cash flows are even worse than those of the wind park alone.

- The reduction of the electricity price during the day, on the contrary, supports the system, increasing the need of energy shifting that the large power and energy capacity of the system can provide. In particular, $50 \%$ of the electric output is provided through the storage system, against the $20 \%$ in the base case, with equivalent operating hours for the compressor that increase from 3000 to 4100 per year. It has to be evidenced also that the benchmark remuneration (i.e., wind park without storage) is strongly reduced ( $62 \mathrm{M} €$ vs. $100 \mathrm{M} €$ ) by this price structure, favoring the installation of a storage system.

Finally, a variation in the operating pressure of the air tank is considered, which influences the depth of the tanks and their size, as well as the compression consumption. This analysis requires a more detailed design of the turbomachinery island, here performed through a simplified approach, keeping constant the polytropic efficiency of the components. The main impact is on the cost of the air reservoir, which reduces almost linearly from $2 \mathrm{M} €$ at 40 bar to less than $1 \mathrm{M} €$ at 120 bar, with minor changes in the costs of the other components, among which the underwater pipe whose length changes from 35 to $50 \mathrm{~km}$. On the other hand, the round-trip efficiency has a maximum between 60 and 80 bar ( $80 \%$ RTE), reducing to $73 \%$ at 120 bar. The global effect is a negligible variation of economics, being the only advantage of higher pressures the smaller size of the underwater structures.

\subsection{Comparison}

In Table 2, the results of the two solutions are compared, reporting the range of values for the best and worst cases obtained. Firstly, the cost structure of the two options leads to a completely different optimal layout: 
- the P2G is a low-power system, with the possibility of exploiting the natural gas infrastructure and store a large amount of energy with a small local buffer;

- $\quad$ the UW-CAES solution is a system with large turbomachinery capacity, being able to completely substitute the wind park both in positive (if no wind is available) and in negative (by adsorbing all the power if it exceeds the grid requirements); local volumes required are large, but mainly located underwater.

Table 2 - Comparison of the main simulation results for P2G and UW-CAES technologies.

\begin{tabular}{|c|c|c|c|c|}
\hline & \multicolumn{2}{|c|}{ P2G } & \multicolumn{2}{|c|}{ UW-CAES } \\
\hline & $\min$ & $\max$ & $\min$ & $\max$ \\
\hline Installed Power $\left[\mathrm{MW}_{\mathrm{e}}\right]$ & 0.5 & 11 & $40(\mathrm{C}), 48(\mathrm{~T})$ & $40(\mathrm{C}), 48(\mathrm{~T})$ \\
\hline Storage $\left[\mathrm{m}^{3}\right]$ & $0\left(\mathrm{H}_{2}\right)$ & $80\left(\mathrm{H}_{2}\right)$ & $\begin{array}{l}13527 \text { (air) } \\
2063 \text { (TES) }\end{array}$ & $\begin{array}{l}32526 \text { (air) } \\
3004 \text { (TES) }\end{array}$ \\
\hline Investment costs $[\mathrm{M} €]$ & 1.02 & 12.38 & $29.56^{(*)}$ & $32.97^{(*)}$ \\
\hline Specific costs $[€ / \mathbf{k W}$ e] & 512 & 1315 & $739^{(*)}$ & $824^{(*)}$ \\
\hline Payback Period [years] & 6 & 20 & 15 & 30 \\
\hline Energy efficiency $[\%]^{(* *)}$ & 60 & 70 & 73.0 & 80.7 \\
\hline
\end{tabular}

From an economic point of view, both solutions are anti-economic, however the P2G system has the best performance at the moment: with an incentive for dispatchable renewable energy provision it becomes competitive with the 'no storage' option. As already mentioned, for both systems the average pay-back times are still too long to be competitive on the market. In addition to the specific costs, also the absolute investment required is different, being an order of magnitude higher on average for the UW-CAES system.

The different energy storage strategy is also worth noticing. The P2G system produces a fuel able to decarbonize a different sector (i.e., current natural gas applications), but with a low economic value (e.g., thermal applications) and low conversion efficiency (about $60 \%$ electricity-to-hydrogen). The UW-CAES is an electrical energy storage with high round-trip efficiency (around 80\%) that is able to provide services to the wind park and balance the grid when required. Both the solutions can potentially act as long-term energy storage, being the self-discharge almost negligible and the power/energy ratio totally free. Anyway, the actual optimized operation, under the economic framework used in this work, does not consider the seasonal storage as a viable option.

\subsubsection{Impact on GHG emission}

On the one hand, the presence of $\mathrm{P} 2 \mathrm{G}$ coupled with the wind farm clearly implies a reduction of the renewable electricity provided to the power grid, as part of the generation is converted into hydrogen heating value. The missing electricity has to be produced by other power plants; for estimating the resulting indirect emissions, it is assumed the average specific $\mathrm{CO}_{2}$ emission of the Italian generation park, equal to $233 \mathrm{~g}_{\mathrm{CO} 2} / \mathrm{kWh}_{\mathrm{e}}$ in 2019 [36]. On the other hand, the hydrogen injected in the natural gas grid partially substitutes the use of fossil fuels in the infrastructure (i.e., both industrial and domestic final uses). A balance between the indirect emissions and the avoided emissions for $\mathrm{NG}$ substitution $\left(205 \mathrm{~g}_{\mathrm{CO} 2} / \mathrm{kWh}_{\mathrm{LHV}}\right)$ can be performed. In all the simulated cases, the first contribute dominates with additional value 
between 5 and $8 \mathrm{kt}_{\mathrm{CO} 2} / \mathrm{y}$ against about $3 \mathrm{kt}_{\mathrm{CO} 2} / \mathrm{y}$ avoided, with a net increase of emissions. However, the higher share of renewable energy expected in the next year will reduce the average emission factor of the energy sector, mitigating this negative effect. In particular, a breakeven specific emission of $125 \mathrm{~g}_{\mathrm{CO} 2} / \mathrm{kWh}_{\mathrm{e}}$ (corresponding to at least $60 \%$ of electricity generation from RES) would make the two contributions equal and the introduction of the P2G system neutral.

On the other hand, the UW-CAES system is a Power-to-Power unit that only shifts the renewable electricity generation in time, with no avoided emissions. Anyway, due to the round-trip efficiency, about $20 \%$ of the stored electricity is lost. Consequently, also in this case, indirect emissions are caused by the additional electricity generation from other power units; with the abovementioned assumptions about the average $\mathrm{CO}_{2}$ emission of the Italian power generation park, about $3 \mathrm{kt}_{\mathrm{CO} 2} / \mathrm{y}$ would be additionally emitted, potentially reduced by an improved share of zero-emission technologies at national level.

\section{Conclusions}

In this work, energy storage solutions based on either a $\mathrm{P} 2 \mathrm{G}$ system with hydrogen injection in the natural gas infrastructure or a UW-CAES system have been applied to the same $48 \mathrm{MW}_{\mathrm{e}}$ off-shore wind park, aiming at reducing the generation variability and exploiting electricity prices variation along the day and the year. The two solutions turned out to be very different, working with installed power capacities and storage volumes of different orders of magnitude.

Apart from the specific values, that strongly depends on the specific case, some general features of the systems can be highlighted. The P2G unit has a small nominal power (always below $11 \mathrm{MW}_{\mathrm{e}}$, i.e., below the $23 \%$ of the wind farm nominal power), is able to exploit the large energy capacity of the natural gas grid and contributes to the decarbonization of a different energy sector. Anyway, the hydrogen has to be valorized with a high price $\left(3 € / \mathrm{kg}_{\mathrm{H} 2}\right.$ at least, with the most favorable assumptions considered in this analysis) to guarantee a positive revenue. The UW-CAES manages higher power flows (the nominal power for the compressor and the turbine are $40 \mathrm{MW}_{\mathrm{e}}$ and $48 \mathrm{MW}_{\mathrm{e}}$, respectively, that is the maximum allowed) being able to fully compensate for unpredictable fluctuation in the wind farm power generation and exploiting balancing tasks with high round-trip efficiency $(>73 \%)$. On the other hand, it requires large volumes and higher initial investment $(>29.6 \mathrm{M} €)$. From the point of view of GHG, both systems in the current conditions increase the average emissions because of indirect emissions due to the reduced RES provided to the grid.

Further developments required to complete the comparison will have to consider complete layouts with the P2P option for the hydrogen-based solution as well as with alternative layouts for the UW-CAES storage systems that have a strong impact on costs. In both cases, the provision of services to the electric grid should be included in the economics. Despite the different outcomes and applications of the technologies, both P2G and UWCAES represent a valid alternative to increase the profitability, dispatchability, and exploitation of non-programmable renewable sources. Both require economic support in the initial phase of development and market diffusion, through incentives on installations and/or through research and development support for the improvement of components.

\section{References}

[1] IRENA. Electricity storage and renewables: Costs and markets to 2030. Abu Dhabi: 2017.

[2] IEA. Harnessing variable renewables: a guide to the balancing challenge. Paris, France: 2011.

[3] Hameer S, van Niekerk JL. A review of large-scale electrical energy storage. Int J Energy Res 2015;39:1179-95. https://doi.org/10.1002/er.3294. 
[4] IEA (International Energy Agency). Technology Roadmap - Energy storage. Paris, France: 2014.

[5] Astolfi M, Guandalini G, Belloli M, Hirn A, Silva P, Campanari S. Preliminary design and performance assessment of an underwater compressed air energy storage system for wind power balancing. J Eng Gas Turbines Power 2020;142. https://doi.org/10.1115/1.4047375.

[6] Wang J, Lu K, Ma L, Wang J, Dooner M, Miao S, et al. Overview of compressed air energy storage and technology development. Energies 2017;10. https://doi.org/10.3390/en10070991.

[7] Sant T, Buhagiar D, Farrugia RN. Evaluating a new concept to integrate compressed air energy storage in spar-type floating offshore wind turbine structures. Ocean Eng 2018;166:232-41. https://doi.org/10.1016/j.oceaneng.2018.08.017.

[8] Pimm AJ, Garvey SD, Drew RJ. Shape and cost analysis of pressurized fabric structures for subsea compressed air energy storage. Proc. Inst. Mech. Eng. Part C J. Mech. Eng. Sci., vol. 225, 2011, p. 1027-43. https://doi.org/10.1177/0954406211399506.

[9] Rhodri J, Marc Costa R. Floating Offshore Wind: Market and Technology Review. UK: 2015.

[10] Equinor. Floating offshore wind in Equinor. Equinor 2017. https://www.equinor.com/en/whatwe-do/floating-wind.html (accessed July 4, 2021).

[11] CleanTechnica. Hywind Scotland, World's First Floating Wind Farm, Performing Better Than Expected 2018. https://cleantechnica.com/2018/02/16/hywind-scotland-worlds-first-floatingwind-farm-performing-better-expected/ (accessed July 4, 2021).

[12] EDP. WindFLoat Atlantic project n.d. https://www.edp.com/en/innovation/windfloat (accessed July 4, 2021).

[13] Campanari S, Colbertaldo P, Guandalini G. Renewable power-to-hydrogen systems and sector coupling power-mobility (in press). In: Van de Voorde M, editor. Hydrog. Prod. Energy Transit., Berlin, Germany: Walter de Gruyter GmbH; 2021. https://doi.org/10.1515/9783110596250-018.

[14] Ursúa A, Gandía LM, Sanchis P. Hydrogen production from water electrolysis: Current status and future trends. Proc. IEEE, vol. 100, Institute of Electrical and Electronics Engineers Inc.; 2012, p. 410-26. https://doi.org/10.1109/JPROC.2011.2156750.

[15] Bertuccioli L, Chan A, Hart D, Lehner F, Madden B, Standen E. Development of Water Electrolysis in the European Union. Lousanne: 2014.

[16] BALANCE EU project. Dynamic modelling of rSOC for grid stabilisation applications. 2019.

[17] STORE\&GO EU project. Analysis on future technology options and on techno-economic optimization. 2019.

[18] Sunfire GmbH. SUNFIRE-HYLINK SOEC - Technical data 2020.

[19] Marie Solbrekke I, Gunnar Kvamstø N, Sorteberg A. Mitigation of offshore wind power intermittency by interconnection of production sites. Wind Energy Sci 2020;5:1663-78. https://doi.org/10.5194/wes-5-1663-2020.

[20] Götz M, Lefebvre J, Mörs F, McDaniel Koch A, Graf F, Bajohr S, et al. Renewable Power-toGas: A technological and economic review. Renew Energy 2016;85:1371-90. https://doi.org/10.1016/j.renene.2015.07.066.

[21] Altfeld K, Pinchbeck D. Admissible hydrogen concentrations in natural gas systems. Gas Energy 2013;March/2013:1-16.

[22] Thema M, Bauer F, Sterner M. Power-to-Gas: Electrolysis and methanation status review. Renew Sustain Energy Rev 2019;112:775-87. https://doi.org/10.1016/j.rser.2019.06.030.

[23] Arothron Ltd. Under Water CAES - Arothron 2019. http://arothron-es.com/ (accessed July 4, 2021).

[24] Environmentalenergy. UWCAES 2018. https://www.environmentalenergyinstitute.com/copyof-yr21 (accessed July 4, 2021).

[25] NREL. System Advisor Model Version 2020.11.29 (SAM 2020.11.29) 2020.

[26] Löfberg J. YALMIP: A toolbox for modeling and optimization in MATLAB. Proc. IEEE Int. Symp. Comput. Control Syst. Des., 2004, p. 284-9. https://doi.org/10.1109/cacsd.2004.1393890.

[27] Gurobi Optimization. Gurobi Optimizer Version 3.0 2020.

[28] Crespi E, Colbertaldo P, Guandalini G, Campanari S. Design of hybrid power-to-power systems for continuous clean PV-based energy supply. Int J Hydrogen Energy 2021;46. https://doi.org/10.1016/j.ijhydene.2020.09.152.

[29] Puertos del Estado. Oceanography - Prediccion de oleaje, nivel del mar; Boyas y mareografos 
2020. http://www.puertos.es/en-us/oceanografia/Pages/portus.aspx (accessed July 1, 2021).

[30] Pellegrini M, Guzzini A, Saccani C. A preliminary assessment of the potential of low percentage green hydrogen blending in the Italian Natural Gas Network. Energies 2020;13:5570. https://doi.org/10.3390/en13215570.

[31] Snam. Snam $\quad$ And 2020. https://www.snam.it/en/energy_transition/hydrogen/snam_and_hydrogen/ (accessed July 4, 2021).

[32] Schmidt O, Gambhir A, Staffell I, Hawkes A, Nelson J, Few S. Future cost and performance of water electrolysis: An expert elicitation study. Int J Hydrogen Energy 2017;42:30470-92. https://doi.org/10.1016/j.ijhydene.2017.10.045.

[33] Glatzmaier G. Developing a Cost Model and Methodology to Estimate Capital Costs for Thermal Energy Storage. Golden, CO (United States): 2011. https://doi.org/10.2172/1031953.

[34] ENTSO-E - European Network of Transmission System Operators. ENTSO-E Transparency Platform - Day-ahead Prices 2021. https://www.entsoe.eu/. (accessed April 7, 2021).

[35] Hu G, Chen C, Lu HT, Wu Y, Liu C, Tao L, et al. A Review of Technical Advances, Barriers, and Solutions in the Power to Hydrogen (P2H) Roadmap. Engineering 2020;6:1364-80. https://doi.org/10.1016/j.eng.2020.04.016.

[36] EEA - European Environment Agency. Greenhouse gas emission intensity of electricity generation 2020. https://www.eea.europa.eu/data-and-maps/daviz/co2-emission-intensity-8 (accessed July 4, 2021). 